\title{
A Procurement Method in Oil Marketing Company Based on Forecast Model and Expectation Criterion
}

\author{
Zhihong Zhao (i) and Yunjin Wang \\ Automation Institute of Lanzhou Petrochemical Company, Lanzhou, China \\ Correspondence should be addressed to Zhihong Zhao; zhaozh11@lzu.edu.cn
}

Received 9 October 2020; Revised 19 February 2021; Accepted 1 March 2021; Published 13 March 2021

Academic Editor: Gordon Huang

Copyright (C) 2021 Zhihong Zhao and Yunjin Wang. This is an open access article distributed under the Creative Commons Attribution License, which permits unrestricted use, distribution, and reproduction in any medium, provided the original work is properly cited.

\begin{abstract}
Within the oil marketing operation, various entities compete and attempt to maximize their profits by providing sufficient supply to meet needs of market. It is an optimal method for oil marketing company operation with a dynamically reasonable inventory to maximize profit under oil price fluctuation and inventory sales lag. In this paper, we study the optimal procurement method of oil marketing company which confirms the reasonable inventory. We build a data fusion model for the GMDH- (group method of data handling-) type neural network and normal distribution forecast results, what is trying to confirm the safety stock (SS). On the basis of the expectation criterion of risk decision and safety stock limit, oil marketing companies can make scientific purchase decision for inventory income. Numerical results reveal that this method has a good effect for inventory income.
\end{abstract}

\section{Introduction}

The economics of an oil marketing company mainly depends on the two the interaction between key elements: the inventory operation and oil price. Traditionally, oil price can be predicted in a short period of time. As two important elements of inventory management, oil sales are affected by market demand, but oil purchase is controlled by oil marketing company. Therefore, the inventory operation of purchase according to the forecast oil price influences the oil asset management of oil marketing company directly. Studies on the oil products purchase management with uncertain prices were scarce as oil prices were relatively stable. However, the oil price has become fluctuate extremely. A procurement method is useful for oil asset appreciation of oil marketing company.

Purchase management needs to be based on a purchase model; EOQ (economic order quantity) is a more general classical model for procurement [1-3]. The limit operation condition of oil marketing company's inventory needs to be determined. The maximum inventory value should not exceed the controllable inventory, and the minimum inventory value should ensure normal sales of company. So, building a practical purchase model of oil marketing company is based on determining the limit inventory and confirming purchases dynamically under the oil price.

However, the limit operation inventory is named safety stock (SS) which to secure inventory performance against operation exception, sales forecast inaccuracy, lead-time change, etc. Forecast models of SS therefore directly results in service level improvements and reduced supply chain costs [4]. In this matter, an accurate and practical forecast model for SS will beneficial to improve the profitability of enterprises.

A lot of approaches are proposed for purchase of oil marketing company, such as simplex method [5], fuzzy set theory [6, 7], MCDA model [8, 9], MCDM model [10], and MRP [11]. But, data-driven decision supports the purchasing operation effectively, and the expectation criterion is one of the common methods. Using expectation criterion will provide a reliable and effective purchase decision for oil sales company.

SS is an important inventory factor, which is a limiting condition in oil marketing company inventory operations [12]. The statistical forecast model method is a classic forecast method [13]. The normal distribution forecast 
model can provide good forecast output value with a large amount of unary input value. The safety stock value is related to sale and purchase. Thus, sale and purchase can be used as input, and the oil inventory operation capacity (including safety stock value) can be predicted through this model. A GMDH-type neural network algorithm is a selforganizing data mine method commonly used to output value forecast, which does not depend on complex modeling [14-19]. Data preprocessing, model generation, and screening of GMDH are all self-adaptive processes, which rely on the interaction within the system to "discover knowledge" and hardly need the user's intervention in the mining process as the organizer. Given the numerous irrelevant variables found in input, the GMDH-type neural network performs self-learning and forecast through screening criteria [20]. Dempster-Shafer (D-S) data fusion function is used to fuse the forecast data from GMDH-type neural network algorithm and normal distribution, which is an effective method for SS determination [21, 22]. Company profitability is directly related to oil price and inventory. However, the oil price fluctuation is extremely difficult to forecast. The maximum company profitability can be acquired through risk decision under the safety stock limitation from this model.

GMDH algorithm and risk decision make the purchase model have the inherent advantages of convenience. Through the previous operation classification data, the result can be calculated without establishing a complex model. This quantitative model has data guiding significance for inventory management, what can avoid the empirical operation.

The contribution of the paper is threefold. First, we presented a method for SS determining of oil inventory operation based on data fusion of GMDH-type neural network algorithm result and normal distribution forecast result. Second, combined with the fluctuating oil price period and using data expectation criterion, an oil purchase decision model for improve inventory income is proposed. Third, numerical results suggest that the oil marketing company can make an economical purchase decision by using this procurement method.

The rest of this paper is structured as follows. Section 2 briefly reviews the related literature. Section 3 introduces the purchase model framework including safety stock determination of oil marketing company based on data fusion, forecast model method of normal distribution, GMDH-type neural network, and the expectation criterion of risk decision. The experimental setup, detailed results, estimate of one oil marketing company, and discussion are described in Section 4. Finally, some concluding remarks and ideas for future work are in Section 5.

\section{Literature Review}

Cachon and Fisher [1], Giannoccaro and Pontrandolfo [2], Netessine and Zhang [3], and Hosoda and Disney [4] proposed the purchase method based on EOQ. Dewi et al. [23] argued that it is an effective method to purchase decisions with safety stock as the constraint and the inventory profitability as the reference.

SS determination is the first step for purchase decisionmaking. Many researchers have been done in developing approaches for SS determination. Fotopoulos et al. [24] present a SS determination method, which is derived by using inequalities on the basis of probability arguments. Yücesan et al. [25] proposed an analytical expression for calculating safety stock. With the growth of computer technology, artificial neural networks to forecast model were widely introduced to SS determination (Zhang et al. [26], Zhang et al. [26], Zhong and Zhang [27], and Zhao and Liu [28]). Artificial intelligence (AI) approaches, such as artificial neural networks (ANN), have good effect for forecast data. According to Yi [29]), Yu [30], and Chen [31], the advantage of BP neural network is that it has strong nonlinear mapping ability to forecast object. Luo [32] proposed an inventory management model based on BP neural network. Adaptive neuro-fuzzy inference systems (ANFIS) has advantages in forecast to fuzzy uncertain systems (Kazemi et al. [33]; Abghari and Sadi [34]; Bakyani et al. [35]). Torkabadi and Mayorga [36] present an inventory management approach based on ANFIS for storage control. Paul et al. [37] developed a method based on ANFIS for inventory level forecasting. In addition, with the help of a large number of operations, SVM can achieve good forecast results (Cui and Curry [38] and Wang et al. [39]). The application of GMDH network algorithm in various scientific fields has achieved good results (Najafzadeh [40]; Najafzadeh, Movahed, and Sarkamaryan et al. [41]; Nkurlu et al. [42]). The GMDH network has the advantages of self-adaptive representation of the forecast object and implementation of training quickly by using the least square method (Najafzadeh and Saberi-Movahed [43]). Furthermore, the researchers argued that GMDH has good performance in accuracy with simply operation. Ongkicyntia and Rahardjo [22] considered that SS is between forecast data and historical data. In this paper, we tried to fuse forecast value based on neural networks (GMDH) and normal distribution (forecast value of historical data) to approximate the SS truth value.

Researchers have developed many different approaches for data fusion to improve data accuracy, include ordered weighted averaging (OWA) (Rezamand et al. [44]), maximum likelihood estimation (Monte-Morenoet al. [45]), Bayes Estimation (Gai and Wang [46]), Kalman filtering (Lanckriet Gert et al. [47]; Caron et al. [48]), robust information fusion (Wang et al. [49]) and Dempster-Shafer (D-S) evidence theory (Varshney [50]; Kam et al. [51]; Radman et al. [52]; Guo and Xu [53]), etc. Moreover, Kordestani et al. [54] proposed a mixed data fusion method based on OWA and Kalman filtering. In contrast, the advantage of D-S evidence theory is that it can separate the strict conditions from the possible ones, so that any lack of information related to a priori probability can be displayed.

As in the previous papers, expected value criteria were introduced, Popovic et al. [55] introduced lots of risk decision method. Ye [56] introduced a weighted method for expected values criteria. Charnetski and Soland [57] presented an expected values criteria model based on numerical integration and Monte Carlo simulation. 
In conclusion, using neural network forecast data and historical data to determine SS makes the data approximate the true value. At the same time, D-S evidence theory is helpful to fuse SS forecast. The expected value criteria are used to simulate the purchase process and then made an economic purchase decision.

\section{Methodology and Modeling Process}

3.1. Framework for Safety Stock Determination Model. Safety stock determination is the first step in the operating model. The operating model is based on two forecast models. The safety stock value (SS) can be obtained through these models. SS can be calculated by using data fusion. The model process is shown in Figure 1.

Data fusion integrates data from different nodes by using various some methods and tools to improve the data accuracy. Weighted coefficient, cluster analysis, and Dempster-Shafer (D-S) reasoning data fusion methods are commonly used in previous studies [21].

The forecast result is calculated by GMDH-type neural network algorithm, so the forecast output value is inclined to theoretical value. By contrast, the normal distribution results use the operated values directly, so the forecast output value from the normal distribution forecast model is inclined to empirical value. Thus, the GMDH-type neural network and normal distribution forecast model output values through data fusion are used to obtain accurate and reasonable safety stock value $[13,19,20,58]$.

According to belief $\left(\mathrm{Bel}_{i}\right)$ and plausibility $\left(\mathrm{Pls}_{i}\right)$ functions of the data, D-S data fusion function is calculated as [58]

$$
S=\frac{\sigma_{1}^{2}}{\sigma_{1}^{2}+\sigma_{2}^{2}} \bar{S}_{1}+\frac{\sigma_{2}^{2}}{\sigma_{1}^{2}+\sigma_{2}^{2}} \bar{S}_{2},
$$

where $\bar{S}_{1}$ is the mean value of the $S_{1}$ set, $\bar{S}_{2}$ is the mean value of the $S_{2}$ set, $\sigma_{1}^{2}$ is variance of the $S_{1}$ set, $\sigma_{2}^{2}$ is variance of the $S_{2}$ set, and $S$ is the fusion value.

The weighted coefficient data fusion method function is calculated as

$$
S=K_{1} S_{1}+K_{2} S_{2}
$$

where $S_{1}$ is $S S$ calculated by GMDH, $S_{2}$ is $S S$ calculated by normal distribution forecast model, $K_{n}$ is the weighted coefficient of $S_{n}\left(K_{1}=\left(\sigma_{\mathrm{GMDH}}^{2} /\left(\sigma_{\mathrm{GMDH}}^{2}+\sigma_{N}^{2}\right)\right), K_{2}\right.$ in the same analogy), and $S$ is the fusion value (SS).

\subsubsection{Safety Stock Based on Forecast Model Method of} Normal Distribution. As shown in Figure 2, the inventory operation is based on EOQ and JIT in theoretical condition [25]. The actual operation is affected when the arrival of the oil is delayed. Thus, a buffer inventory must be considered to ensure the normal storage operation. SS of oil storage based on EOQ is regarded as the buffer inventory.

Purchase and sale are the two main factors, which directly affect SS. Theoretically, the minimum safety stock value $\left(S S_{\min }\right)$ appears at the front of the purchase point, as shown in Figure 2. Mapping exists between sale and $S S_{\min }$. As shown in Figure $3, S S_{\min }$ has changed with sale change because of mapping. Thus, $S S_{\min }$ obeys the same distribution. $S S_{\text {min }}$ function is calculated as

$$
\begin{aligned}
S S & =\mathscr{F}(S, P), \\
S S & =K * \sigma_{S}, \\
S S_{\min } & =K_{\min } * \sigma_{S},
\end{aligned}
$$

where $K_{\min }$ is the safety factor and $\sigma_{S}$ is the standard deviation of sale.

The maximum safety stock value $\left(S S_{\max }\right)$ is similar to $S S_{\min }$. Mapping exists between purchase and $S S_{\max }$. As shown in Figure $4, S S_{\max }$ obeys the same distribution of purchases. The $S S_{\max }$ is calculated as

$$
\begin{aligned}
S S & =\mathscr{F}(S, P), \\
S S & =K * \sigma_{S}, \\
S S_{\max } & =S_{\max }-K_{\max } * \sigma_{P},
\end{aligned}
$$

where $S_{\max }$ is the maximum oil inventory capacity, $K_{\max }$ is the safety factor, and $\sigma_{p}$ is the standard deviation of purchase.

According to the historical data of the same period, $K_{\min }$ and $K_{\max }$ are confirmed by standardisation.

3.1.2. Safety Stock Based on GMDH-Type Neural Network. According to the actual work of inventory management, there is no accurate calculation value of safety stock, which is usually determined by empirical value. The factors that affect the reasonable inventory mainly include two categories: one is the oil depot factor, and the other is the demand factor.

So, the empirical value of SS is used as the output value of GMDH. The GMDH self-organization model needs to embrace all kinds of operated variables as much as possible to find the relationship between variables that is not easy to find. According to the actual operation of inventory management and control, the factors of oil depot (available stock, bottom oil, ratio of gas and diesel, and transportation time) and demand factor (daily demand) have an important impact on the determination of safety stock. Those values are used as the input value of GMDH. And, GMDH is trained with the minimum mean square error of global neurons as the stopping criterion.

The preparation of the data classification is significant. The classification of the actual data based on SS is shown in Table 1:

The GMDH software, Knowledge Miner, GMDH Shell, and self-made programme of MATLAB are the most common software used to calculate SS.

3.2. Risk Decision. Oil prices are adjusted according to a certain period of time. This period is called the oil price window period. Given the classic inventory operation model (i.e., EOQ) [25], the oil inventory operating model is shown in Figure 5. 


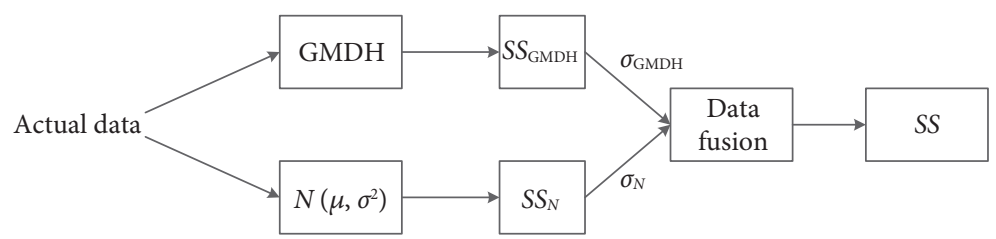

Figure 1: Framework for the SS determination model.

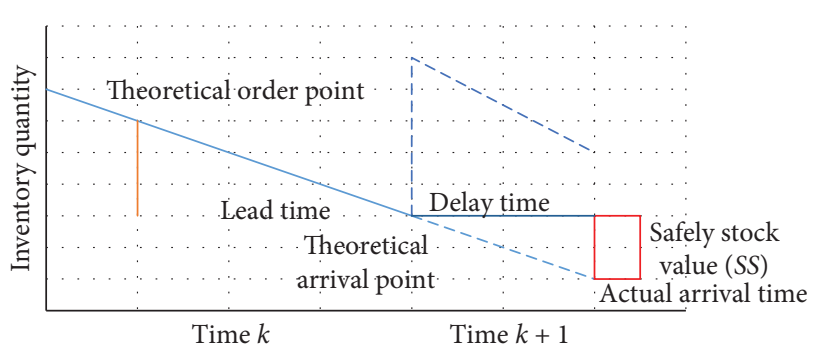

- Theoretical inventory operation for time $K$

- - Theoretical inventory operation for time $K+1$

FIgURE 2: SS based on EOQ.

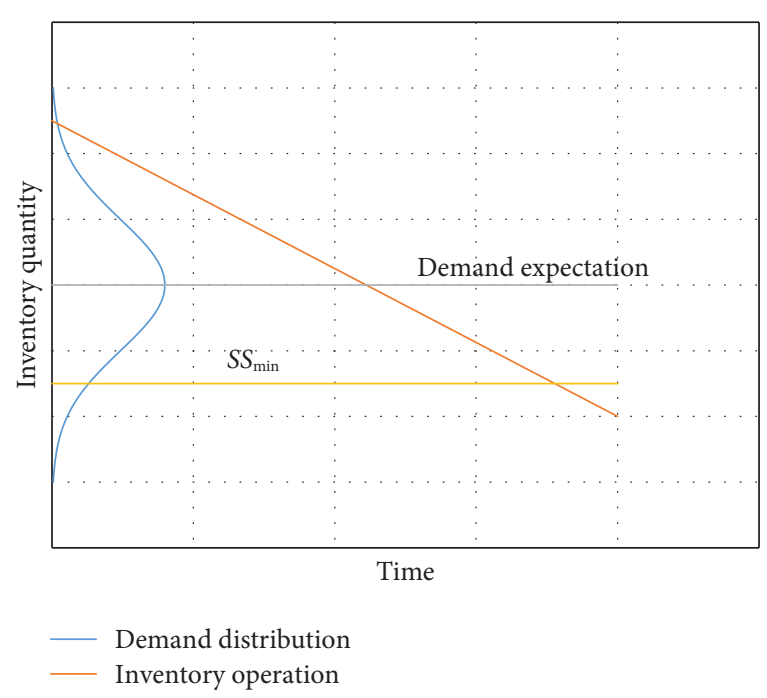

FIGURE 3: Relationship between $S S_{\min }$ and sale.

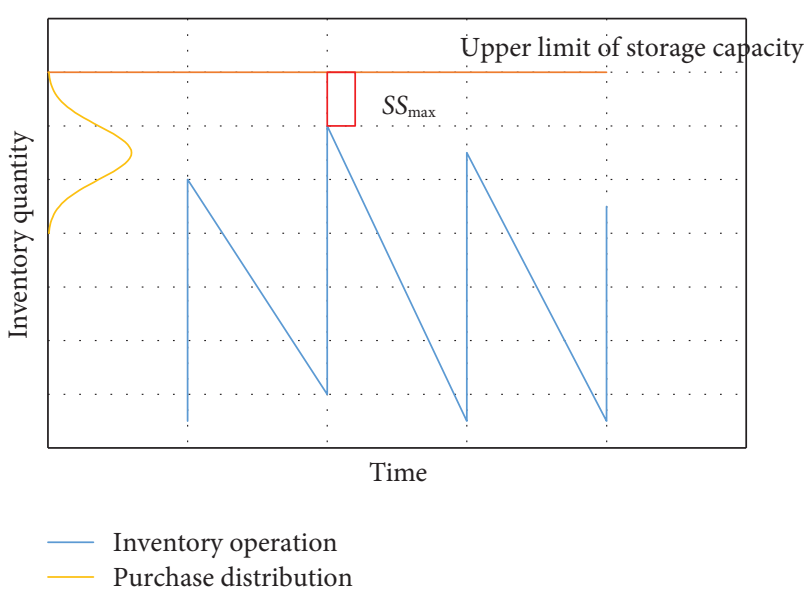

FIGURE 4: Relationship between $S S_{\max }$ and purchase.
Table 1: Classification of input data.

\begin{tabular}{lc}
\hline$X 1$ & Available stock value \\
\hline$X 2$ & Daily demand \\
$X 3$ & Bottom oil \\
$X 4$ & Ratio of gas and diesel \\
$X 5$ & Transportation time (max) \\
$X 6$ & Transportation time (min) \\
$X 7$ & On-order inventory \\
\hline
\end{tabular}

Bottom oil is the oil in the bottom of the tank and the pipe.

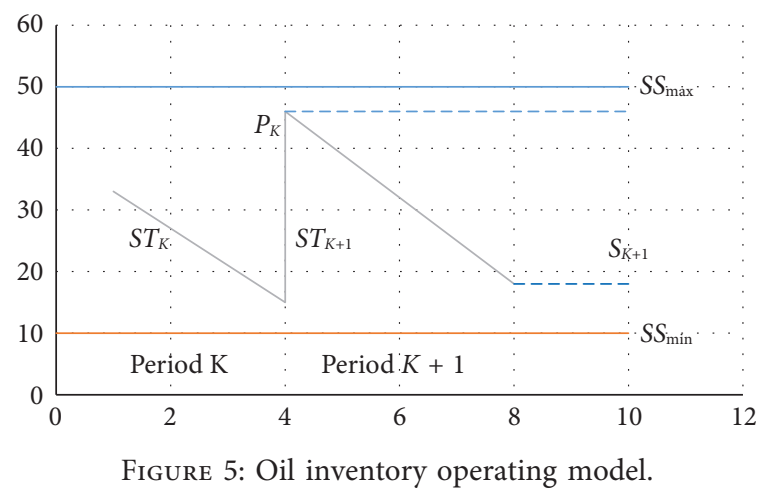

For the maximum profitability under the safety stock limit, the function is calculated as follows:

$$
\begin{aligned}
Z= & \max \left(S T_{K+1}+S_{K+1}\right) * P R_{K+1}, \\
& \left\{\begin{array}{l}
S T_{K+1}=S T_{k}+P_{K}-S_{K+1}, \\
S T_{k}+P_{K} \leq S S_{\max }, \\
S T_{K+1} \geq S S_{\min },
\end{array}\right.
\end{aligned}
$$

where $S T_{K+1}$ is the inventory value in the end of period $K+1$, $P R_{K+1}$ is the oil price of period $K+1, P_{K}$ is the purchase value in period $K$, and $S_{K+1}$ is the sale value in period $K+1$.

The income of inventory in a period is calculated is calculated as follows:

$$
\begin{aligned}
S V_{K} & =V E_{K}-V B_{K}, \\
V E_{K} & =\left(S T_{K-1 \_e}+P_{K}-S_{K}\right) \times P R_{K}+S_{K} \times\left(P R_{K}+P R_{K-\text { Add }}\right), \\
V B_{K} & =\left(S T_{K-1 \_e}+P_{K}\right) \times P R_{K-1},
\end{aligned}
$$

where $S V_{K}$ is the income of inventory in a period $K, V E_{K}$ is the inventory value in the end of period $K, V B_{K}$ is the inventory value at the beginning of period $K, S T_{K-1_{-} e}$ is the inventory in the end of period $K-1$, and $P R_{K-\text { Add }}$ is the transport price. 
The income of inventory function is rewritten as follows:

$$
S V_{K}=\left(S_{K-1 \_e}+P_{K}\right) \times \Delta P R+S_{K} \times P R_{K-\text { Add }},
$$

where $\triangle P R$ is the change of oil price between window period $K-1$ and window period $K$.

In Function (5), $S_{K}$ is beyond the oil marketing company control. $P_{K}$ is an independent variable, under the oil marketing company control. $S_{K-1_{-}}$is the dependent variable from purchase and sale. Thus, the definition of the purchase is the key for maximum profitability.

Purchase and oil price are the key to inventory operation. In actual operation, oil marketing companies can accurately forecast next oil price window period. Moreover, oil marketing companies can forecast the subsequent oil price window period after the first forecast. However, the probability of accuracy forecast is not more than 0.5. Determining the purchasing strategy can be considered the expectation criterion [13]. The expectation criterion for purchase with oil price is listed in Table 2:

The lag effect, which is the effect of the inventory of period $K$ on the inventory income of period $K+1$, greatly influences the inventory income. The expectation criterion has a good effect on eliminating the lag effect. Thus, the expectation criterion of the inventory operation management model supports the purchase decision in each period for oil marketing companies.

\section{Simulation and Results}

In this section, an operation analysis on one oil marketing company is presented on the basis of the purchase model.

4.1. SS by Forecast Model of Normal Distribution. Firstly, the trend of the sale market in the past year is characterised by calculating the standard deviation of sale in the same year. The sale data in 2018 of an oil marketing company are shown in Table 3:

Thus, the standard deviation of 2018 is $\sigma_{Y}=47,517.08$.

Secondly, the calculation of the standard deviation of sale in the last quarter includes gas and diesel. The standard deviation defines the demand of gas and diesel. The oil marketing company sale data within approximately three months are shown in Table 4:

Thus, the standard deviation of gas and diesel is $\sigma_{Q-\text { gas }}=389$, 96.25 and $\sigma_{Q \text {-diesel }}=181,66.56$, respectively. Combined with the past year trends and recent demands, the standard deviation of sale is calculated using equation (2): $\sigma_{\text {gas }}=\left(\sigma_{Y}^{2} /\left(\sigma_{Y}^{2}+\sigma_{Q-\text { gas }}^{2}\right)\right)$ $\sigma_{Y}+\left(\sigma_{\text {gas }}^{2} /\left(\sigma_{Y}^{2}+\sigma_{\mathrm{Q}-\text { gas }}^{2}\right)\right) \sigma_{\mathrm{Q}-\text { gas }}=44,087.83 ; \sigma_{\text {diesel }}=\left(\sigma_{Y}^{2} / \stackrel{\left(\sigma_{Y}^{2}+\right.}{\sigma_{Y}^{2}}+\right.$ $\left.\left.\sigma_{Q-\text { diesel }}^{2}\right)\right) \sigma_{Y}+\left(\sigma_{\text {gas }}^{2} /\left(\sigma_{Y}^{2}+\sigma_{Q \text {-diesel }}^{2}\right)\right) \sigma_{Q-}$ diesel $=43,774.13$.

Using the equation (3), the following is calculated: $S S_{\text {min-gas }}=K_{\text {gas }} \times \sigma_{\text {gas }} ; S S_{\text {min-diesel }}=K_{\text {diesel }} \times \sigma_{\text {diesel }}$.
TABle 2: Expectation criterion for oil marketing company purchase.

\begin{tabular}{|c|c|c|c|c|c|c|c|}
\hline \multirow[b]{3}{*}{ Schemes $S_{i}$} & \multicolumn{7}{|c|}{ Probability of oil price } \\
\hline & \multicolumn{3}{|c|}{ Period $K$} & \multicolumn{3}{|c|}{ Period $K+1$} & \multirow[b]{2}{*}{$\begin{array}{c}\text { Expected } \\
\text { value }\end{array}$} \\
\hline & Rise & Keep & $\begin{array}{l}\text { Fall } \\
\text { Inco }\end{array}$ & $\begin{array}{l}\text { Rise } \\
P_{2 R} \\
\text { mes }\end{array}$ & $\begin{array}{c}\text { Keep } \\
P_{2 K}\end{array}$ & $\begin{array}{l}\text { Fall } \\
P_{2 F}\end{array}$ & \\
\hline$S_{1}$ (bulk) & $a 11$ & & & $b 11$ & $b 12$ & $b 13$ & $Z_{1}$ \\
\hline $\begin{array}{l}S_{2} \\
\text { (appropriate) }\end{array}$ & & $a 22$ & & $b 21$ & $b 22$ & $b 23$ & $Z_{2}$ \\
\hline$S_{3}$ (bit) & & & $a 33$ & $b 31$ & $b 32$ & $b 33$ & $Z_{3}$ \\
\hline
\end{tabular}

The calculation method of the safety factor is $K=\left(\left(4 \times \sum_{1 \leq i \leq 3} S_{i}\right) / \sum_{1 \leq i \leq 12} S_{i}\right)$. This formula integrates the standardised proportion of the annual sale volume within approximately three months. Thus, $K_{\text {gas }}=0.9448$ and $K_{\text {diesel }}=1.0910$.

In the actual operation of the oil inventory, the bottom oil is needed. Thus, the safety stock value $\left(S S_{\min }\right)$ is rewritten as follows: $S S_{\min }=\left(S S_{\text {min-gas }}+S R_{\text {gas }}\right)+\left(S S_{\text {min-diesel }}+S R_{\text {diesel }}\right)$, where $S R_{\text {gas }}$ is the bottom oil of gas and $S R_{\text {diesel }}$ is the bottom oil of diesel.

Thus, $S S_{\min }=(41,652.7+33,603)+(47,755.8+25,304)=$ $148,315.4$ (tons).

Similar with $S S_{\max }$, the standard deviation of purchase in the past year is calculated by characterising the trend of purchase in the past year. The purchased data in 2018 of an oil marketing company are shown in Table 5:

Thus, the standard deviation of 2018 is $\sigma_{Y}=40,703.96$. The purchase data within approximately three months of the same company are shown in Table 6.

Thus, the standard deviations of gas and diesel are $\sigma_{\mathrm{Q}-\text { gas }}=6,262.00$ and $\sigma_{\mathrm{Q} \text {-diesel }}=26,569.58$, respectively. Combined with the past year trends and recent demands, the standard deviation of purchase is calculated using equation (2): $\sigma_{\text {gas }}=39,907.65 ; \sigma_{\text {diesel }}=36,480.89$.

Similar to the sale safety factor, the following are obtained: $K=\left(\left(4 \times \sum_{1 \leq i \leq 3} P_{i}\right) / \sum_{1 \leq i \leq 12} P_{i}\right), \quad K_{\text {gas }}=0.9412$, and $K_{\text {diesel }}=0.9984$.

Using equation (4), the following is obtained: $S S_{\max }=$ $S_{\max }-\left(K_{\text {gas }} \times \sigma_{\text {gas }}+K_{\text {diesel }} \times \sigma_{\text {diesel }}\right)=601000-(37,559.94$ $+36,423.91)=527,016.1$ (tons).

4.2. SS by GMDH. No. 92 gasoline oil depot data of one day in January 2018 are provided in Table 7. By using the GMDH software, the K-G functions and plot can be obtained. The $\mathrm{K}-\mathrm{G}$ functions can be calculated as follows [8]:

$$
\begin{aligned}
& Y_{92-\min }=2.705 X_{7}^{2}-0.9046 e^{-1} X_{1} X_{7}-1.797 e^{-3} X_{1}^{2}-9.21 e^{-2} X_{7}+1.675 e^{-1} X_{1}+0.738 e^{-1} X_{3}+0.9708 e^{-1} X_{2} \\
& Y_{92-\max }=1.513 e^{-1} X_{1}+12.1 X_{2}+2.198 X_{3} .
\end{aligned}
$$


TABLE 3: 2018 sale data of the oil marketing company.

\begin{tabular}{|c|c|c|c|c|c|c|}
\hline Month & January & February & March & April & May & June \\
\hline Amount (tons) & 822,200 & 710,888 & 831,425 & 794,995 & 768,670 & 788,468 \\
\hline Month & July & August & September & October & November & December \\
\hline Amount (tons) & 783,105 & 774,119 & 693,660 & 861,895 & 722,430 & 782,089 \\
\hline
\end{tabular}

TABLE 4: Sale data within approximately three months of the oil marketing company.

\begin{tabular}{lccc}
\hline (tons) & October & November & December \\
\hline Gas & 435,656 & 340,316 & 382,897 \\
Diesel & 426,239 & 382,114 & 399,192 \\
\hline
\end{tabular}

TABLE 5: 2018 purchase data of the oil marketing company.

\begin{tabular}{|c|c|c|c|c|c|c|}
\hline Month & January & February & March & April & May & June \\
\hline Amount (tons) & 769,606 & 714,151 & 833,799 & 822,721 & 801,155 & 829,424 \\
\hline Month & July & August & September & October & November & December \\
\hline Amount (tons) & 808,090 & 720,351 & 797,552 & 725,203 & 769,182 & 772,630 \\
\hline
\end{tabular}

TABle 6: Purchase data within approximately three months of the oil marketing company.

\begin{tabular}{lccc}
\hline$(t)$ & October & November & December \\
\hline Gas & 392,037 & 376,862 & 386,385 \\
Diesel & 333,166 & 392,320 & 386,245 \\
\hline
\end{tabular}

The forecast SS of No. 92 gasoline oil provided by the GMDH software is indicated in Figure 6.

Moreover, $\quad \sigma_{92-\min }=3,585 ; \quad \sigma_{92-\max }=6,215$; $S S_{92-\min }=98,998$ (tons); and $S S_{92-\max }=179,318$ (tons).

Similar to No. 92 gasoline oil, $\sigma_{95-\min }=943$; $\sigma_{95-\max }=1,998 ; S S_{95-\max }=42,029$ (tons); $S S_{95-\text { min }}=15,292$ (tons); $\quad \sigma_{0-\min }=2,111 ; \quad \sigma_{0-\max }=8,663 ; \quad S S_{0-\max }=284,796$ (tons); and $S S_{0-\min }=84,943$ (tons). The forecast SS of No. 95 gasoline oil and No. 0 diesel oil is indicated in Figure 7.
According to the GMDH software, the fitting coefficients (R-squared) are $R_{92-\min }^{2}=0.803 ; R_{92-\max }^{2}=0.785 ; R_{95-\min }^{2}=$ $0.925 ; R_{95-\max }^{2}=0.967 ; R_{0-\min }^{2}=0.752$; and $R_{0-\max }^{2}=0.876$. in the result of those R-squared, since the sales of No. 95 gasoline is less, the influence of randomness is not much, so the curve fitting degree is better.

4.3. SS Data Fusion. The data of $S S_{(\min )}$ of January 2018 based on forecast model of normal distribution are calculated as follows: $\sigma_{N \text {-gas }}=44,087.83 ; \sigma_{N \text {-diesel }}=43,774.13$; $S S_{N-\text { min-gas }}=75,255.7 ; \quad S S_{N-\text { min-diesel }}=73,059.8 . S S_{\text {min }}$ includes the bottom oil.

The data of $S S_{\text {min }}$ based on GMDH are calculated as follows: $\quad \sigma_{\mathrm{GMDH} \text {-gas }}=3,261 ; \quad \sigma_{\mathrm{GMDH} \text {-diesel }}=2,111 ; \quad S S_{\mathrm{GMDH}-}$ $\min -$ gas $=114,290 ; S S_{\mathrm{GMDH}-\text { min-diesel }}=84,943$.

Using equation (1), the following is calculated:

$$
S S_{\text {min-gas }}=\frac{\sigma_{N-\text { gas }}^{2}}{\sigma_{N-\text { gas }}^{2}+\sigma_{\mathrm{GMDH}-\text { gas }}^{2}} S S_{N-\text { min-gas }}+\frac{\sigma_{\mathrm{GMDH}-\mathrm{gas}}^{2}}{\sigma_{N-\text { gas }}^{2}+\sigma_{\mathrm{GMDH}-\text { gas }}^{2}} S S_{\mathrm{GMDH}-\text { min-gas }}=75,468 \text { (tons). }
$$

Similar to $S S_{\text {min-gas }}, S S_{\text {min-diesel }}=73,087$ (tons). Thus, $S S_{\min }=148,555$ (tons).

The data of $S S_{\max }$ of January 2018 based on normal distribution are calculated as follows: $\sigma_{N}=38347.68$; $S S_{N-\max }=527,016.1$. The data of $S S_{\max }$ based on GMDH are calculated as follows: $\sigma_{\mathrm{GMDH}}=7,720 ; S S_{\mathrm{GMDH}-\max }=506,144$.

Using equation (1), $S S_{\max }=526,203$ (tons).

4.4. Purchase Decision Using Expectation Criterion. In the actual situation, an oil company can accurately forecast the next oil price period. The probability of forecast accuracy of the subsequent periods after the first forecast is not more than 0.5 . The gas operation actual data (windows periods 0 , 1 , and 2 of 2018) of the same company are listed in Table 9:

4.4.1. Inventory Income of Period 1 from Purchases in Period 0 . At the end of the period $0, S S_{\text {max-gas }}=254,950$ (tons) and $S S_{\text {min-gas }}=75,468$ (tons). The purchase is ordered in period 0 by the given oil price (i.e., 3149), and purchase arrival is in period 1 .

The purchase schemes in period 0 are calculated as follows (suppose that $S_{0_{-} e}=150,000$ [tons]):

$$
\begin{aligned}
& P_{\text {bulk }}+S_{0 \_e}=S S_{\text {max }- \text { gas }}+S_{k} \text {, so } P_{\text {bulk }}=344,950 \text { (tons) } \\
& P_{\text {appropriate }}=P_{\text {actual }}=207,708 \text { (tons) }
\end{aligned}
$$


TABLe 7: No. 92 gasoline oil depot data (10,000 tons).

\begin{tabular}{|c|c|c|c|c|c|c|c|c|c|}
\hline \multirow[t]{3}{*}{ Oil depot } & \multicolumn{2}{|c|}{ SS (empirical) } & \multirow{3}{*}{$\begin{array}{c}\text { Available } \\
\text { stock value } \\
X 1\end{array}$} & \multirow{3}{*}{$\begin{array}{l}\text { Daily demand } \\
\text { X2 }\end{array}$} & \multirow{3}{*}{$\begin{array}{l}\text { Bottom oil } \\
\text { X3 }\end{array}$} & \multirow{3}{*}{$\begin{array}{c}\text { Ratio of gas } \\
\text { and diesel } \\
\text { X4 }\end{array}$} & \multicolumn{2}{|c|}{$\begin{array}{l}\text { Transportation } \\
\text { time (day) }\end{array}$} & \multirow{3}{*}{$\begin{array}{c}\text { On-order } \\
\text { inventory } \\
X 7\end{array}$} \\
\hline & \multirow[t]{2}{*}{ Min } & \multirow[t]{2}{*}{$\operatorname{Max}$} & & & & & $\operatorname{Max}$ & Min & \\
\hline & & & & & & & $X 5$ & X6 & \\
\hline A & 0.35 & 0.43 & 0.63 & 0.0442 & 0.03 & 1.3446 & 8 & 6 & 0.19564 \\
\hline B & 0.3 & 0.5 & 0.69 & 0.0437 & 0.05 & 1.1012 & 8 & 6 & 0.19564 \\
\hline C & 0.3 & 0.36 & 0.55 & 0.0522 & 0.06 & 1.1018 & 8 & 6 & 0.19564 \\
\hline D & 0.21 & 0.29 & 0.43 & 0.0453 & 0.06 & 1.1807 & 8 & 6 & 0.146 \\
\hline E & 1.77 & 2.5 & 3.53 & 0.1211 & 0.28 & 0.7928 & 8 & 6 & 1.02711 \\
\hline F & 0.34 & 0.83 & 1.12 & 0.0125 & 0.12 & 1.6648 & 11 & 6 & 0.292 \\
\hline G & 0.18 & 0.27 & 0.99 & 0.0192 & 0.05 & 1.2887 & 11 & 6 & 0.219 \\
\hline $\mathrm{H}$ & 0.22 & 0.47 & 1.09 & 0.0206 & 0.05 & 1.0626 & 8 & 6 & 0.219 \\
\hline I & 0.3 & 0.36 & 1.09 & 0.0488 & 0.11 & 1.4261 & 8 & 6 & 0.365 \\
\hline $\mathrm{J}$ & 0.04 & 0.07 & 0.1 & 0.006 & 0 & 2.5754 & 11 & 11 & 0.003 \\
\hline K & 0.29 & 0.57 & 0.81 & 0.0333 & 0.04 & 1.3946 & 8 & 5 & 0.03 \\
\hline $\mathrm{L}$ & 0.32 & 0.78 & 1.11 & 0.0313 & 0.04 & 1.783 & 8 & 5 & 0.03 \\
\hline M & 0.09 & 0.22 & 0.31 & 0.0274 & 0.02 & 1.068 & 8 & 5 & 0.009 \\
\hline $\mathrm{N}$ & 0.32 & 0.46 & 0.66 & 0.037 & 0.05 & 1.2689 & 8 & 5 & 0.03 \\
\hline $\mathrm{O}$ & 0.2 & 0.25 & 0.36 & 0.0149 & 0.01 & 1.6912 & 8 & 5 & 0.02 \\
\hline $\mathrm{P}$ & 0.05 & 0.05 & 0.85 & 0.053 & 0.05 & 0.9807 & 6 & 5 & 0 \\
\hline Q & 0.25 & 0.31 & 0.44 & 0.0092 & 0.04 & 1.4914 & 6 & 5 & 0.04 \\
\hline $\mathrm{R}$ & 0.17 & 0.59 & 1.05 & 0.0636 & 0.11 & 0.4816 & 6 & 5 & 0.01 \\
\hline S & 0.29 & 1 & 1.21 & 0.0287 & 0.1 & 1.3365 & 7 & 5 & 0.02 \\
\hline $\mathrm{T}$ & 0.28 & 1.1 & 1.2 & 0.0254 & 0.11 & 2.021 & 7 & 5 & 0.02 \\
\hline $\mathrm{U}$ & 0.25 & 0.61 & 0.87 & 0.0345 & 0.07 & 0.9576 & 7 & 5 & 0.03 \\
\hline $\mathrm{V}$ & 0.34 & 0.58 & 0.75 & 0.0297 & 0.06 & 1.4601 & 8 & 5 & 0.04 \\
\hline
\end{tabular}

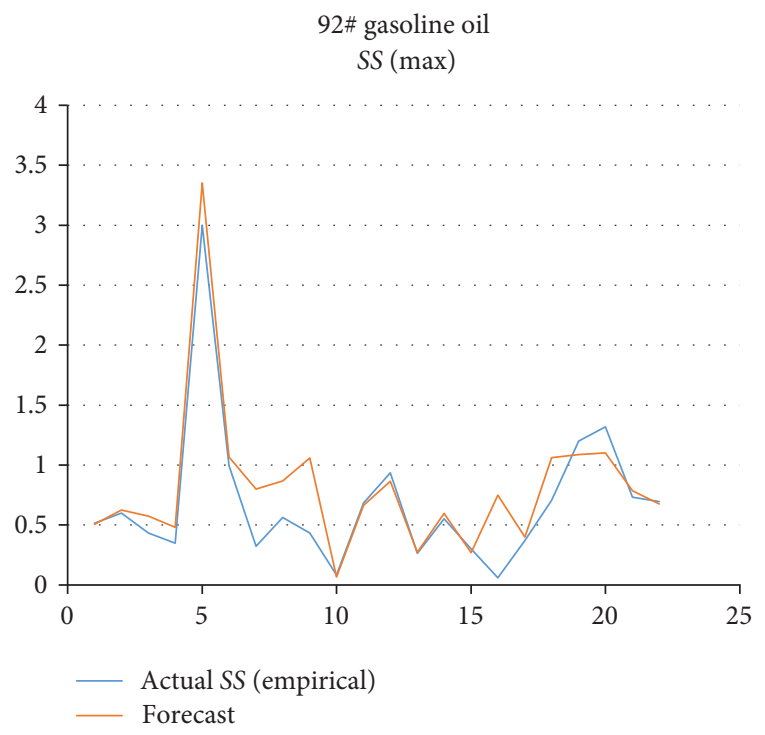

(a)

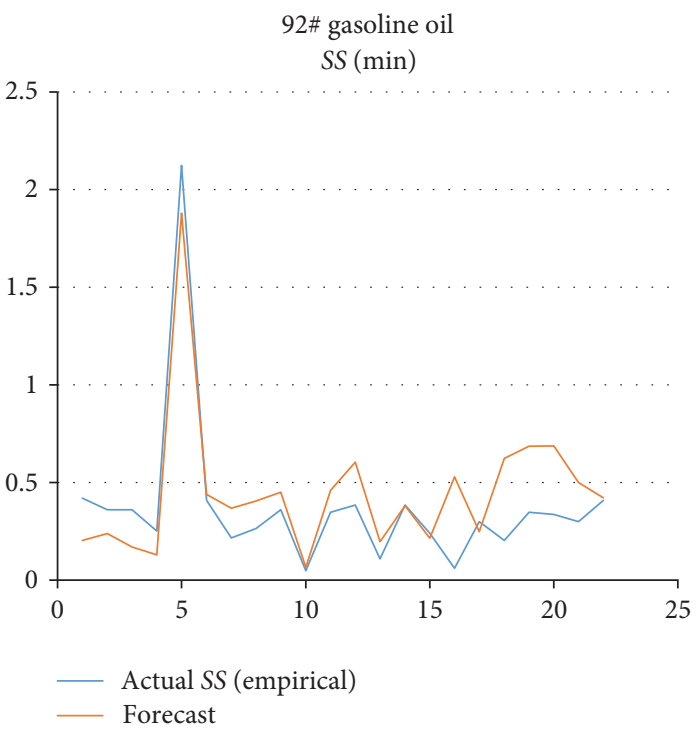

(b)

Figure 6: Forecast SS of No. 92 gasoline oil based on GMDH software. 


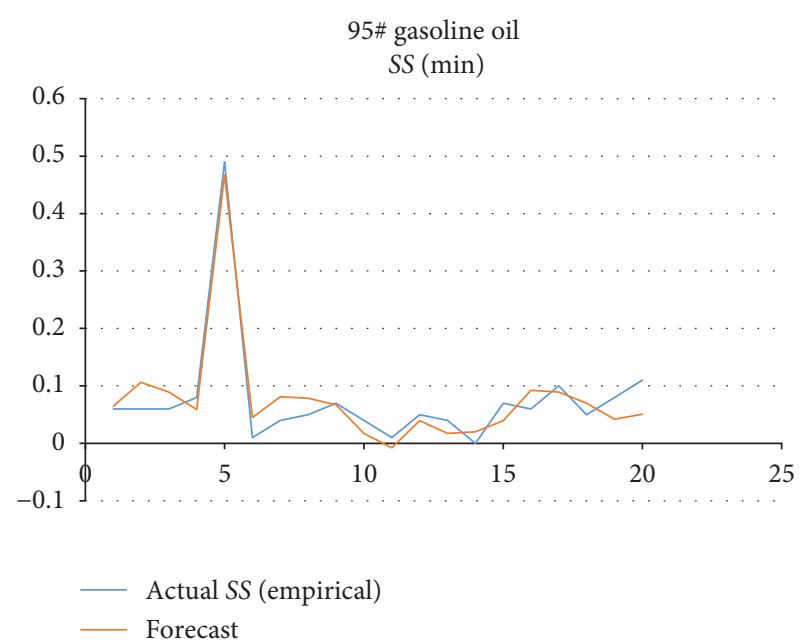

(a)

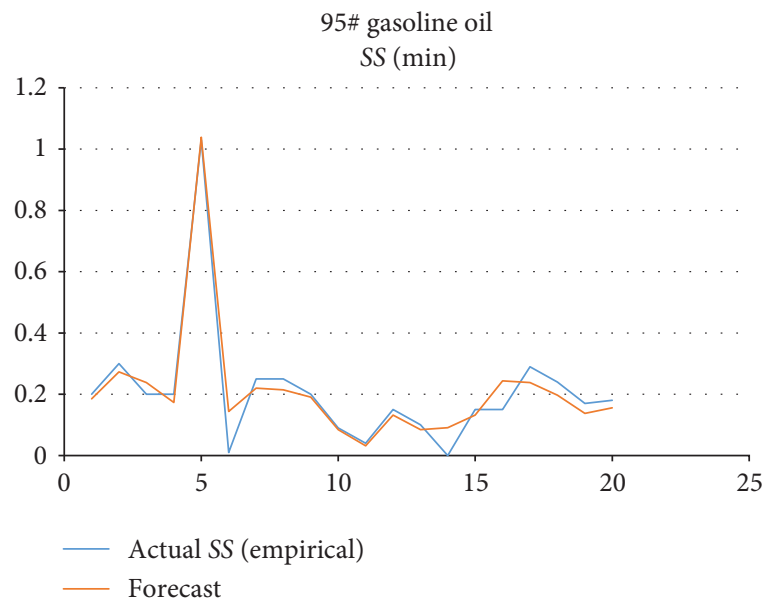

(c)

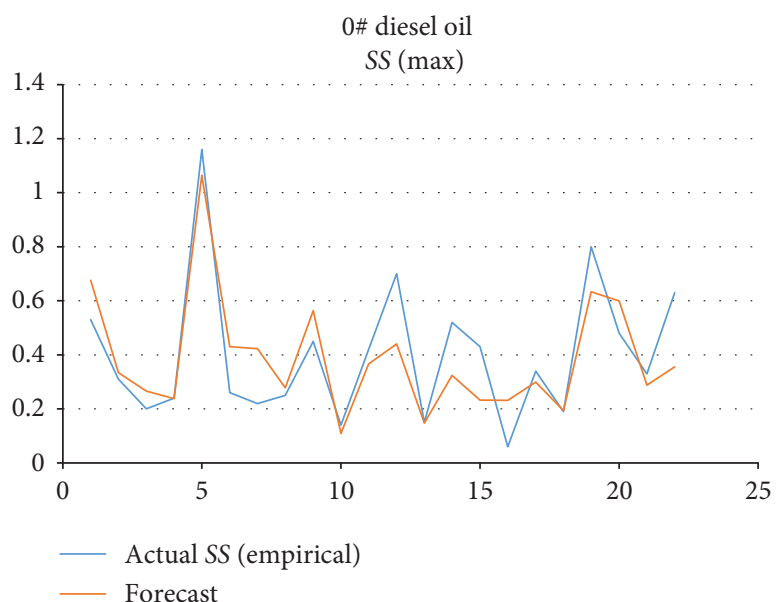

(b)

0\# diesel oil SS (max)

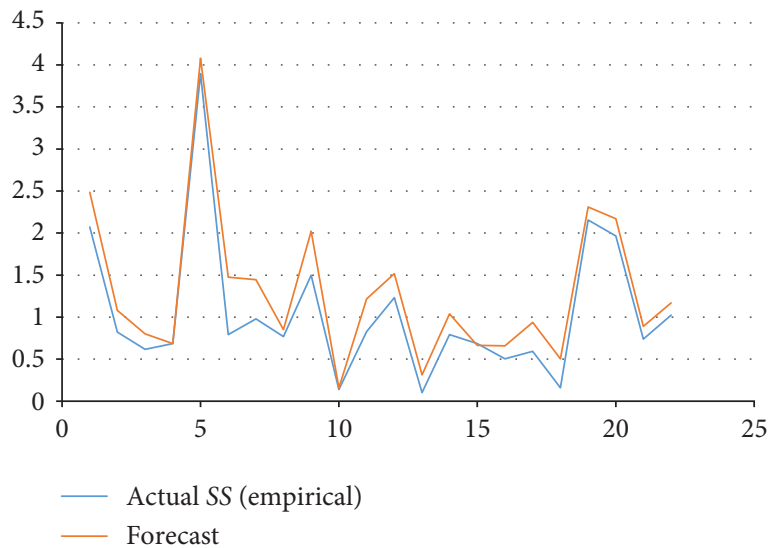

(d)

FIGURE 7: Forecast SS of No. 95 gasoline oil and no. 0 diesel oil based on GMDH software.

$P_{\text {bit }}+S_{0 \_e}=S S_{\text {min-gas }}+S_{k}$; thus, $P_{\text {bit }}=165,468$ (tons)

According to equation (7), $P R_{1-\text { Add }}=100$ (Yuan). Thus, $S V_{1}=P_{0} \times \Delta P R+S_{1} \times P R_{1-\text { Add }}$. The inventory income of period 1 from purchases is calculated as follows:

$$
\begin{aligned}
& a 1=(150,000+344,950) * 50+23,500,000 \approx 48,200,000 \\
& a 2=(150,000+207,708) * 50+23,500,000 \approx 41,385,400 \\
& a 3=(150,000+165,468) * 50+23,500,000 \approx 39,000,000
\end{aligned}
$$

4.4.2. Inventory Income of Period 2 from Purchases in Period 0 . Virtual purchases for period 2 based on the oil price probability in the same period are used to obtain the correct purchase decision in period 0 . The purchase decision in period 1 is based on the oil price in period 2 and oil price probability in period 3. The purchase decision in each window period is repeated in turn.

The purchase decision is based on the following rules: (1) when the oil price is decreasing, the inventory closes the minimum safety stock; (2) when the oil price is increasing, the inventory closes the maximum safety stock; and (3) when the oil price is uncertain, the purchase is based on the forecasted sale.

The inventory at the end of period 1 is calculated as follows:

$$
\begin{aligned}
& S_{1 \_e} \quad(\text { bulk in period } 0)=(150,000+344,950)- \\
& 235,000=259,950 \text { (tons) } \\
& S_{1 \_e}(\text { appropriate in period } 0)=(150,000+207,708)- \\
& 235,000=122,708 \text { (tons) } \\
& S_{1 \_e} \quad(\text { bit in period } 0)=(150,000+165,468)- \\
& 235,000=80,468 \text { (tons) }
\end{aligned}
$$

The purchases made in period 2 according to the purchase decision rules are shown in Table 10:

The oil price probability is as follows: rise $=0.05$; keep $=0.15$; down $=0.5$; unknown $=0.3$. Thus, Table 10 is based on the expectation criterion rewritten in Table 11.

Thus, according to equation (7), $S V_{2}=P_{2} \times \Delta P R+$ $S_{2} \times P R_{2 \text {-Add }}$. The inventory income of period 2 from purchases is calculated as follows:

$$
S_{K 2} \times P R_{2-\text { Add }}=200,000 * 100=20,000,000
$$




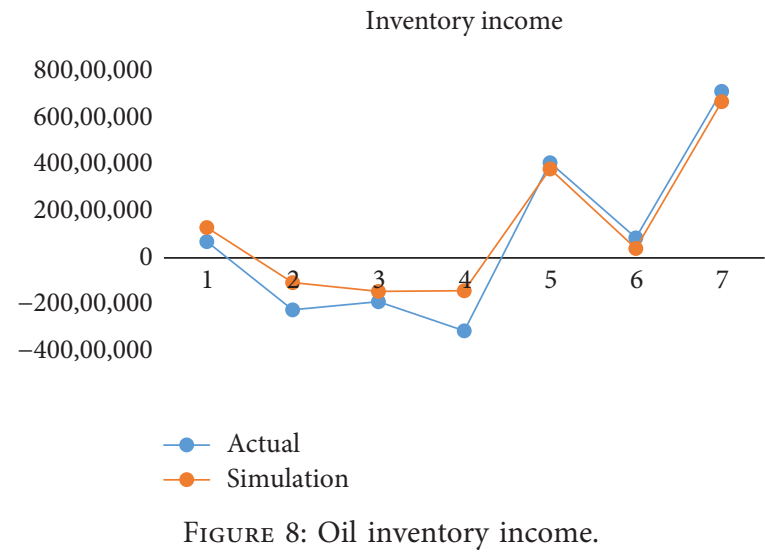

TABLE 8: SS from different data sources.

\begin{tabular}{lcccc}
\hline \multirow{2}{*}{ SS } & \multicolumn{2}{c}{ Min } & \multicolumn{2}{c}{ Max } \\
& Value & Relative error (\%) & Value & Relative error (\%) \\
\hline Actual (empirical) & 155700 & & 481845 & \\
From normal distribution & 148315 & 4.74 & 527016 & 9.37 \\
From GMDH & 199233 & 27.96 & 506143 & 5.04 \\
Data fusion & 148555 & 4.59 & 526203 & 9.21 \\
\hline
\end{tabular}

SS from different data sources are shown in Table 8. We can find that the each forecast value is generally consistent with the actual (empirical) value. We can also find that, through data fusion, we can better correct the impact of data randomness on the forecast data.

TABLe 9: Gas operation actual data of the oil marketing company.

\begin{tabular}{lccc}
\hline & Period 0 & Period 1 & Period 2 \\
\hline Actual oil Price (Yuan/ton) & 3,149 & $(3,149)+50$ & $(3,149+50)-140$ \\
Purchase (ton) & 207,708 & 224,064 & 200,000 \\
Forecast Sale (ton) & & 240,000 & 235,000 \\
Actual Sale (ton) & & & \\
\hline
\end{tabular}

TABLE 10: Virtual purchase for period 2.

\begin{tabular}{|c|c|c|c|c|c|}
\hline \multirow{3}{*}{ Schemes $S_{i}$} & \multicolumn{5}{|c|}{$\begin{array}{l}\text { Period } 2 \\
\text { Probability }\end{array}$} \\
\hline & Rise (close the $S S_{\max }$ ) & $\begin{array}{r}\text { Keep (median value) } \\
\text { Purchase }\end{array}$ & Down (close the $\left.S S_{\min }\right)$ & Unknown & \multirow[t]{2}{*}{ Expected value } \\
\hline & $P_{1 R}$ & $P_{1 K}$ & $P_{1 D}$ & $P_{1 U n}$ & \\
\hline $\bar{S}$ & 195,000 & 105,259 & 15,518 & 200,000 & $Z_{1}$ \\
\hline$S_{2}$ & 332,242 & 242,501 & 152,760 & 200,000 & $Z_{2}$ \\
\hline$S_{3}$ & 374,482 & 284,741 & 195,000 & 200,000 & $Z_{3}$ \\
\hline
\end{tabular}

$b 1=(259,950+93,298) *$

$(-140)+20,000,000 \approx-29,454,699$

$b 2=(122,708+189,367) *$

$(-140)+20,000,000 \approx-23,690,535$

$b 3=(80,468+218,935) *$

$(-140)+20,000,000 \approx-21,916,455$

The inventory expectation income is shown in Table 12:
According to Table 12, the bulk purchase is the optimization scheme in period 1.

Using the above method, the oil marketing company purchase is simulated. The simulation results are compared with the actual operation as shown in Table 13.

The oil inventory income is as indicated in Figure 8. The total income $82,940,610$ of the model is greater than $55,547,840$ of the actual total income. From the oil 
TABLE 11: Expectation purchase for period 2.

\begin{tabular}{|c|c|c|c|c|c|}
\hline \multirow{6}{*}{ Schemes $S_{i}$} & \multicolumn{5}{|c|}{ Oil price status } \\
\hline & \multirow{2}{*}{\multicolumn{5}{|c|}{$\begin{array}{c}\text { Period } 2 \\
\text { Probability }\end{array}$}} \\
\hline & & & & & \\
\hline & Rise (close the $S S_{\max }$ ) & Keep (median value) & Down (close the $\left.S S_{\min }\right)$ & Unknown & \multirow{3}{*}{ Expected value } \\
\hline & & Purchase & & & \\
\hline & 0.05 & 0.15 & 0.5 & 0.3 & \\
\hline$S_{1}$ & 195,000 & 105,259 & 15,518 & 200,000 & 93,298 \\
\hline$S_{2}$ & 332,242 & 242,501 & 152,760 & 200,000 & 189,367 \\
\hline$S_{3}$ & 374,482 & 284,741 & 195,000 & 200,000 & 218,935 \\
\hline
\end{tabular}

TABLE 12: Inventory expectation income.

\begin{tabular}{lccc}
\hline Schemes $S_{i}$ & \multicolumn{3}{c}{ Incomes } \\
& Period 1 & Period 2 & (max) $18,745,301$ \\
$S_{1}$ (bulk) & $48,200,000$ & $-29,454,699$ & $17,694,865$ \\
$S_{2}$ (appropriate) & $41,385,400$ & $-23,690,535$ & $17,083,545$ \\
$S_{3}$ (bit) & $39,000,000$ & $-21,916,455$ & \\
\hline
\end{tabular}

TABle 13: Purchase simulation and inventory income.

\begin{tabular}{|c|c|c|c|c|c|c|c|c|}
\hline & & Period1 & Period2 & Period3 & Period4 & Period5 & Period6 & Period7 \\
\hline Oil price & & $3,149+50$ & $3199-140$ & $3059-190$ & $2869+0$ & $2869+170$ & $3039+50$ & $3089+255$ \\
\hline Sales & & 235,000 & 240,500 & 240,000 & 258,000 & 251,800 & 259,800 & 262,080 \\
\hline \multirow{2}{*}{ Purchase } & Actual & 224,064 & 175,000 & 199,000 & 282,000 & 210,000 & 221,000 & 321,000 \\
\hline & Simulation & 344,950 & 56,018 & 240,000 & 256,402 & 401,580 & 125,820 & 444,680 \\
\hline \multirow{2}{*}{ Inventory of end period } & Actual & 139,064 & 158,564 & 134,000 & 223,000 & 240,200 & 171,200 & 279,920 \\
\hline & Simulation & 259,950 & 75,468 & 75,468 & 73,870 & 223,650 & 79,670 & 262,270 \\
\hline \multirow{2}{*}{ Income in period } & Actual & $6,953,200$ & $-22,198,960$ & $-18,760,000$ & $-31,220,000$ & $40,834,000$ & $8,560,000$ & $71,379,600$ \\
\hline & Simulation & $12,997,500$ & $-10,565,520$ & $-14,338,920$ & $-14,035,300$ & $38,020,500$ & $3,983,500$ & $66,878,850$ \\
\hline
\end{tabular}

inventory income, this method has a good effect for inventory income.

4.5. Results and Discussion. This paper proposed model is that the data are all from the actual operation data without any transformation. The model not only ensures the inventory in a reasonable operation scope by forecast model of GMDH-type neural network, normal distribution, and data fusion but also gets good profitability by risk decision. Meanwhile, the calculation results from this model provide guidance for oil asset management.

However, the dissatisfied consistency of curves is shown in Figures 6 and 7. Generally, consistency is an important criterion for forecast models. Especially, in this model, the fitting coefficient of fitting curve based on GMDH algorithm can well represent this standard. The input value of the GMDH comes from empirical factors. So, the accuracy of the model will be improved by adding empirical correction coefficient.

Moreover, a gap exists in the magnitude of the standard deviation between the GMDH method and the forecast model of normal distribution. The gap influences the effectiveness of data fusion. The utilisation of the forecast model of the normal distribution in each oil depot results in a rigorous forecast model. The operation granularity depends on the proposed model based on EOQ.

\section{Conclusion and Future Works}

In this study, a purchase model of oil marketing companies is presented. This model is based on GMDH-type neural network, forecast model of normal distribution, data fusion, and risk decision. A GMDH-type neural network has an advantage in researching uncertainty in complex systems. The purchase and sale of oil marketing companies follow normal distribution. The normal distribution forecast model for safety stock determination is created according to the mapping relationship of the normal distribution. Two kinds of forecast results with data fusion are explored to determine accurate and reliable forecast results. The safety stock and expectation criterion of risk decision provide a scientific operating model for the inventory operation management of oil marketing companies.

However, the model needs to forecast the safety stock firstly. Fuzzy set theory has a good response to uncertainty. Meanwhile, Choquet integral and OWA operator are good data fusion methods for SS. Therefore, in the future, we will 
use a large number of inventory income data to explore the optimal fusion approach by experimental method. In addition, the purchase decision-making comes from a set of discrete values of expectation criterion results. If we can use a better algorithm to simulate the purchasing profitability curve and get the extreme value, we will make a better purchasing decision.

\section{Data Availability}

The data used to support the findings of this study are available from the corresponding author upon request.

\section{Conflicts of Interest}

The authors declare that they have no conflicts of interest.

\section{References}

[1] G. P. Cachon and M. Fisher, "Supply chain inventory management and the value of shared information," Management Science, vol. 46, no. 8, pp. 1032-1048, 2000.

[2] I. Giannoccaro and P. Pontrandolfo, "Inventory management in supply chains: a reinforcement learning approach," International Journal of Production Economics, vol. 78, no. 2, pp. 153-161, 2002.

[3] S. Netessine and F. Zhang, "Positive vs. Negative externalities in inventory management: implications for supply chain design," Manufacturing \& Service Operations Management, vol. 7, no. 1, pp. 58-73, 2005.

[4] T. Hosoda and S. M. Disney, "Impact of market demand misspecification on a two-level supply chain," International Journal of Production Economics, vol. 121, no. 2, pp. 739-751, 2009.

[5] X. Cui and Z. Lin, "One kind based on simplex method purchase decision model and solution," in Proceedings of the 2010 International Conference on Optics, Photonics and Energy Engineering, pp. 180-183, Wuhan, China, May 2010.

[6] C. Stanciulescu, P. Fortemps, M. Installé, and V. Wertz, "Multiobjective fuzzy linear programming problems with fuzzy decision variables," European Journal of Operational Research, vol. 149, no. 3, pp. 654-675, 2003.

[7] B. Zhang, G. Bu, and Y. Cao, "The construction and application of enterprise purchase decision-making models," in Proceedings of the International Conference on Engineering and Business Management (EBM 2010), pp. 1312-1314, Chengdu,China, March 2010.

[8] D. O. T. Environment, "MULTI-CRITERIA analysis-a manual," Economic History Working Papers. The London School of Economics and Political Science, London, UK, 2009.

[9] A. H. Abdullah, A.-P. Holtorf, M. Al-Hussaini, J. Lemay, and M. Alowayesh, "Stakeholder driven development of a multicriteria decision analysis tool for purchasing off-patent pharmaceuticals in Kuwait," Journal of Pharmaceutical Policy and Practice, vol. 12, p. 9, 2019.

[10] C.-T. Lin, C.-B. Chen, and Y.-C. Ting, "A decision support system for a purchasing model using an integration of MCDM and linear programming," Journal of Information and Optimization Sciences, vol. 31, no. 6, pp. 1249-1261, 2010.

[11] S. Zhu, Study on the Pricing and Quantity Decision of Online Retailers Based on EOQ Model, Shanghai Jiao Tong University, Shanghai, China, 2017.
[12] B. Huang, "Safe stock setting for car assembly enterprises," Logistics Technology, vol. 30, pp. 125-126, 2011.

[13] J.-p. Zhang, "Application of normal distribution function in forecast of product ion inactivation," Journal of Science of Teachers' College and University, vol. 5, pp. 67-69, 2001.

[14] L. Xie, J. Xiao, Y. Hu, H. Zhao, and Y. Xiao, "China's energy consumption forecasting by GMDH based auto-regressive model," Journal of Systems Science and Complexity, vol. 30, no. 6, pp. 1332-1349, 2017.

[15] K. M. Dogan and E. Gunpinar, "Learning yacht hull adjectives and their relationship with hull surface geometry using GMDH-type neural networks for human oriented smart design," Ocean Engineering, vol. 145, pp. 215-229, 2017.

[16] Z. Li, The improvements of GMDH algorithm and research of the prediction and early warning on coal market system, Vol. 5, Nanjing University of Aeronautics and Astronautics, Nanjing, China, 2013.

[17] H. Javdanian, A. Heidari, and R. Kamgar, "Energy-based estimation of soil liquefaction potential using GMDH algorithm," Iranian Journal of Science and Technology, Transactions of Civil Engineering, vol. 41, pp. 283-295, 2017.

[18] M. Lu, "An improved GMDH algorithm and its application," Soft Science, vol. 4, pp. 17-20, 2008.

[19] J.-p. Chen, Y. Yi-min, H.-z. Zhang, and X.-s. Chen, “A neural network learning algorithm based on GMDH model," Journal of Yunnan University, vol. 30, no. 6, pp. 569-574, 2008.

[20] A. G. Ivakhnenko and G. A. Ivakhnenko, "The review of problems solvable by algorithms of the group method of data handling (GMDH)," Pattern Recognition \& Image Analysis, vol. 5, no. 4, pp. 527-535, 1995.

[21] Y.-m. Zhou, Study on the Key Technologies of Wireless Sensor Network Based Greenhouse Ranges Monitoring \& Control System and it's Realization, Vol. 6, Zhejiang University, Hangzhou, China, 2009.

[22] A. Ongkicyntia and J. Rahardjo, "Replenishment strategy based on historical data and forecast of safety stock," in Proceedings of the 2017 International Conference on Soft Computing, Intelligent System and Information Technology (ICSIIT), IEEE, Denpasar, Indonesia, September 2017.

[23] E. K. Dewi, M. Dahlui, D. Chalidyanto, and T. N. Rochmah, "Achieving cost-efficient management of drug supply via economic order quantity and minimum-maximum stock level," Expert Review of Pharmacoeconomics and Outcomes Research, vol. 20, no. 3, pp. 289-294, 2020.

[24] S. Fotopoulos, M.-C. Wang, and S. S. Rao, "Safety stock determination with correlated demands and arbitrary lead times," European Journal of Operational Research, vol. 35, no. 2, pp. 172-181, 1988.

[25] E. Yücesan, C. h. Chen, E. Saliby, J. L. Snowdon, and C. F. Silva, "A simulation model to validate and evaluate the adequacy of an analytical expression for proper safety stock sizing," in Proceedings of the 2002 Winter Simulation Conference, San Diego, CA, USA, December 2002.

[26] L. Zhang, D. Wang, and L. Chang, "A model on forecasting safety stock of ERP based on BP neural network," in Proceedings of the IEEE International Conference on Management of Innovation \& Technology, IEEE, Bangkok, Thailand, September 2008 .

[27] W. Zhong and L. Zhang, "The prediction research of safety stock based on the combinatorial forecasting model," in Proceedings of the International Conference on Computational Science \& Engineering, Porto, Portugal, October 2015.

[28] P. Zhao and J. Liu, "The product safety stock prediction method based on artificial neural network," in Proceedings of 
the IEEE International Conference of Information Science and Management Engineering, IEEE, Xi'an, China, September 2010.

[29] J. Yi, "BP neural network prediction-based variable-period sampling approach for networked control systems-ScienceDirect," Applied Mathematics and Computation, vol. 185, no. 2, pp. 976988, 2007.

[30] S. Yu, K. Zhu, and F. Diao, "A dynamic all parameters adaptive BP neural networks model and its application on oil reservoir prediction," Applied Mathematics and Computation, vol. 195, no. 1, pp. 66-75, 2008.

[31] B. Chen, J. Wang, and S. Chen, "Prediction of pulsed GTAW penetration status based on BP neural network and D-S evidence theory information fusion," International Journal of Advanced Manufacturing Technology, vol. 48, no. 1-4, pp. 83-94, 2010.

[32] B. Luo, H. Wan-jie, and S. Yang, "Application of BP neural networks in inventory dynamic modeling," Journal of Chongqing University (Natural Science Edition), vol. 28, 2005.

[33] S. M. R. Kazemi, M. M. S. Hoseini, S. Abbasian-Naghneh et al., "An evolutionary-based adaptive neuro-fuzzy inference system for intelligent short-term load forecasting," International Transactions in Operational Research, vol. 21, 2013.

[34] S. Z. Abghari and M. Sadi, "Application of adaptive neuro-fuzzy inference system for the prediction of the yield distribution of the main products in the steam cracking of atmospheric gasoil," Journal of the Taiwan Institute of Chemical Engineers, vol. 44, no. 3, pp. 365-376, 2013.

[35] A. E. Bakyani, H. Sahebi, M. M. Ghiasi et al., "Prediction of $\mathrm{CO} 2$-oil molecular diffusion using adaptive neuro-fuzzy inference system and particle swarm optimization technique," Fuel, vol. 181, no. oct.1, pp. 178-187, 2016.

[36] A. M. Torkabadi and R. V. Mayorga, "Optimization of supply chain based on JIT pull control policies: an integrated fuzzy AHP and ANFIS approach," WSEAS Transactions On Computers, vol. 16, 2017.

[37] S. K. Paul, A. Azeem, and A. K. Ghosh, "Application of adaptive neuro-fuzzy inference system and artificial neural network in inventory level forecasting," International Journal of Business Information Systems, vol. 18, no. 3, pp. 268-284, 2015.

[38] D. Cui and D. Curry, "Prediction in marketing using the support vector machine," Marketing Science, vol. 24, 2005.

[39] W. Wang, C. Men, and W. Lu, "Online prediction model based on support vector machine," Neurocomputing, vol. 71, no. 4-6, pp. 550-558, 2008.

[40] M. Najafzadeh, "Neuro-fuzzy GMDH systems based evolutionary algorithms to predict scour pile groups in clear water conditions," Ocean Engineering, vol. 99, no. may 1, pp. 85-94, 2015.

[41] M. Najafzadeh, F. S. Movahed, and S. Sarkamaryan, "NF-GMDHBased self-organized systems to predict bridge pier scour depth under debris flow effects," Marine Georesources and Geotechnology, vol. 36, 2017.

[42] B. M. Nkurlu, C. Shen, S. Asanteokyere et al., "Prediction of permeability using group method of data handling (GMDH) neural network from well log data," Energies, vol. 13, 2020.

[43] M. Najafzadeh and F. Saberi-Movahed, "GMDH-GEP to predict free span expansion rates below pipelines under waves," Marine Georesources \& Geotechnology, vol. 37, pp. 1-18, 2018.

[44] M. Rezamand, M. Kordestani, R. Carriveau, D. S. K. Ting, and M. Saif, "An integrated feature-based failure prognosis method for wind turbine bearings," IEEE/ASME Transactions on Mechatronics, vol. 25, 2020.

[45] E. Monte-Moreno, M. Chetouani, M. Faundez-Zanuy, and J. Sole-Casals, "Maximum likelihood linear programming data fusion for speaker recognition," Speech Communication, vol. 51, no. 9, pp. 820-830, 2009.

[46] Y. L. Gai and Y. P. Wang, "Data fusion and Bayes estimation algorithm research," Applied Mechanics and Materials, vol. 347-350, pp. 2620-2624, 2013.

[47] R. G. Lanckriet Gert, D. B. Tijl, C. Nello, and I. Jordan Michael, "A statistical framework for genomic data fusion," Bioinformatics, vol. 20, no. 16, pp. 2626-2635, 2004.

[48] F. Caron, E. Duflos, D. Pomorski et al., "GPS/IMU Data Fusion using multisensor Kalman filtering: introduction of contextual aspects," Information Fusion, vol. 7, no. 2, pp. 221-230, 2017.

[49] J. Wang, Y. Mao, Z. Li et al., "Robust fusion estimation for multisensor uncertain systems with state delay based on data-driven communication strategy," IEEE Access, vol. 8, 2020.

[50] P. K. Varshney, Distributed Detection and Data Fusion, Springer, Berlin, Germany, 1997.

[51] M. Kam, Q. Zhu, and W. S. Gray, "Optimal data fusion of correlated local decisions in multiple sensor detection systems," IEEE Transactions on Aerospace and Electronic Systems, vol. 28, no. 3, pp. 916-920, 1992.

[52] M. Radman, M. Moradi, and C. Ali, "Multi-feature fusion approach for epileptic seizure detection from EEG signals," IEEE Sensors, vol. 99, 2020.

[53] T. Guo and Z. Xu, "Data fusion of multi-scale representations for structural damage detection," Mechanical Systems And Signal Processing, vol. 98, pp. 1020-1033, 2018.

[54] M. Kordestani, M. Dehghani, B. Moshiri, and M. Saif, "A new fusion estimation method for multi-rate multi-sensor systems with missing measurements," IEEE Access, vol. 8, 2020.

[55] V. M. Popovic, B. M. Vasic, B. B. Rakicevic et al., "Optimisation of maintenance concept choice using risk-decision factor-a case study," International Journal of Systems Ence, vol. 43, no. 10-12, pp. 1913-1926, 2012.

[56] J. Ye, "Expected value method for intuitionistic trapezoidal fuzzy multicriteria decision-making problems," Expert Systems with Applications, vol. 38, no. 9, pp. 11730-11734, 2011.

[57] J. R. Charnetski and R. M. Soland, "Multiple-attribute decision making with partial information: the expected-value criterion," Naval Research Logistics Quarterly, vol. 26, no. 2, 1979.

[58] J. Liu, J. Huang, R. Sun, H. Yu, and R. Xiao, "Data fusion for multi-source sensors using GA-PSO-BP neural network," IEEE Transactions On Intelligent Transportation Systems, pp. 1-16, 2020. 